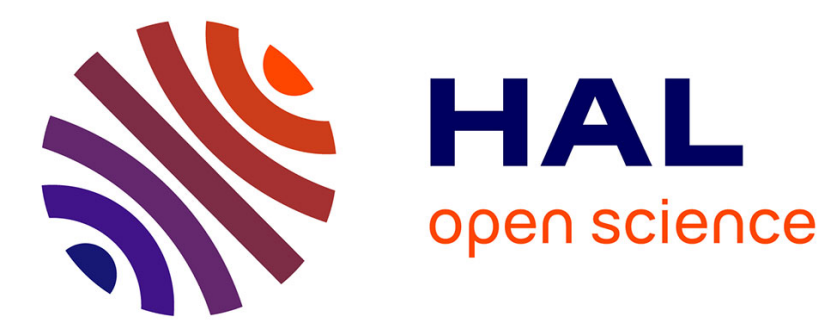

\title{
An Empirical Investigation of the Practices and Challenges Specific to International User Studies
}

\author{
Sabine Madsen, Lene Nielsen, Heidi Hautopp, Iben Jensen
}

\section{To cite this version:}

Sabine Madsen, Lene Nielsen, Heidi Hautopp, Iben Jensen. An Empirical Investigation of the Practices and Challenges Specific to International User Studies. 15th Human-Computer Interaction (INTERACT), Sep 2015, Bamberg, Germany. pp.132-148, 10.1007/978-3-319-22698-9_10 . hal-01609381

\section{HAL Id: hal-01609381 \\ https://hal.inria.fr/hal-01609381}

Submitted on 3 Oct 2017

HAL is a multi-disciplinary open access archive for the deposit and dissemination of scientific research documents, whether they are published or not. The documents may come from teaching and research institutions in France or abroad, or from public or private research centers.
L'archive ouverte pluridisciplinaire HAL, est destinée au dépôt et à la diffusion de documents scientifiques de niveau recherche, publiés ou non, émanant des établissements d'enseignement et de recherche français ou étrangers, des laboratoires publics ou privés. 


\title{
An Empirical Investigation of the Practices and Challenges Specific to International User Studies
}

\author{
Sabine Madsen ${ }^{1}$, Lene Nielsen ${ }^{1}$, Heidi Hautopp ${ }^{2}$, Iben Jensen ${ }^{2}$ \\ ${ }^{1}$ IT University of Copenhagen, Rued Langgaardsvej 7, 2300 Copenhagen S, Denmark \\ ${ }^{2}$ Aalborg University, A C. Meyers Vænge 15, 2450 Copenhagen SV, Denmark \\ sabinemadsen@live.dk, leneditu. dk \\ heidi.hautopp@gmail.com, ij@learning.aau.dk
}

\begin{abstract}
In today's globalized world, it is increasingly important for comp anies to gain knowledge about international markets and to understand the differences and similarities between international users. As a result, international user studies have become more common. However, they still pose a challenge for most companies. In this paper, we present the results of an empirical investigation of how companies conduct international user studies. We describe the empirical findings in detail, with an emphasis on the practices and challenges that are specific to the process of doing international user studies. Key findings concern where, geographically, companies choose to collect data; the scope and scale of the studies; as well as the preferred data collection methods and employed control mechanisms. Our research shows that strategic/pragmatic considerations, perceived differences in national culture, and concerns about data quality shape and delimit the approach that companies take to international user studies.
\end{abstract}

Keywords. Design; International user studies; Application; Practice-study

\section{Introduction}

The HCI field has traditionally focused on two key research areas, namely (1) methods, tools and guidelines for designing and testing interfaces to enhance the us ability hereof and (2) approaches for understanding the users and the context and situational aspects that influence their use of a given (IT) product or service. Within both of these research areas, the implications of globalization and the internationalization of products and services have over the years become important topics of study [2, 3, 14, 16].

Our research is positioned within the second stream of research concerned with approaches for understanding users and contextual product use. In particular, we aim to contribute to the HCI literature with insights about how companies conduct interna- 
tional userstudies to get a foundation for meeting the needs of and designing products and services for users on international markets.

An earlier research project discovered that companies found it difficult to decide which markets to approach and how to incorporate cultural differences when communicating the findings from the user studies as personas [10]. Looking at the literature within $\mathrm{HCl}$ very little address these aspects in a scientific way and most address data collection and communication from an experience-based perspective, see e.g. $[13,14]$. An exception is [1], who draws on empirical data to propose a conceptual framework that, among other things, assists designers in global companies in planning user studies that take local and cultural aspects into account.

The purpose of this research is to investigate how companies conduct international user studies; and more specifically to identify the practices and challenges that are particular to the process of collecting data and presenting insights about users on international markets.

The research is based on a qualitative interview study with 15 practitioners from 11 different companies. All interviews were held in Denmark, either in Danish companies that have users and subdivisions around the world or in Danish subdivisions of large international corporations. This means that what is considered "international" is seen from a Danish perspective.

\section{On culture and intercultural communication}

All user studies are concerned with understanding the important differences and similarities among users. However, one of the aspects that make international user studies different from national user studies is that they are explicitly concerned with culture and intercultural communication. Thus, international user studies require attention to cultural differences and similarities during the planning and data collection phases of the study. Moreover, an important outcome of these studies is an increased understanding of which cultural differences and similarities that exist among users on different markets and which of these that are - and are not - important to take into account when designing a given product.

Recent theories point out that in today's globalized world it is useful to think about culture as a concept and phenomenon that refers to much more than just national culture [7]. This allows for other understandings of the significant differences and similarities between groups of people and of the complexity of peoples' everyday lives. A complex understanding of culture facilitates ways of grouping people based on their everyday practices and the communities (i.e. cultures) they participate in; e.g., by focusing on their practices with regard to work, leisure, sport, parenting, language, gender, and religion [8].

A complex understanding of culture does not exclude a focus on national culture; rather the emphasis is on, for example, understanding what it means to be Danish and at the same time that there are many ways in which to be Danish. However, as the theories stress, even for people with a high level of intercultural competence it remains a challenge to avoid interpretations, linguistic expressions, and actions that are 
informed by more simplistic national and geographical stereotypes. This is due to, among other things, the strong influence of the very notion of national culture as well as to the often more one-sided representations and discourses presented in the media.

This complex understanding of culture is very different from the understanding of culture as represented by methods, tools and guidelines for designing interfaces as suggested by e.g. [9] or the application of methods on new frontiers as described by e.g. $[12,15]$.

In this paper, we use the distinction between the concept of national culture and the complex understanding of culture as our theoretical foundation for understanding the role that perceptions of cultural differences and similarities play when companies collect and present data about international users.

\section{$3 \quad$ Research method}

The research presented in this paper is based on a qualitative interview study with 15 user researchers from 11 different companies. The aim of the interviews was to investigate how companies collect and present data about users on international markets.

The companies/interviewees were selected from the involved researchers' professional network based on the following criteria. (1) The most important criterion was that they were operating on international markets. (2) The second criterion was that they had experience with international user studies and/or that they were using methods (such as, e.g. the persona method or segmentation into target groups) to delineate and incorporate user insights into their work and design processes.

The interviews were carried out from February - April 2014. All interviews took place in Denmark, either in Danish companies that have users and subdivisions around the world or in Danish subdivisions of large international companies.

The interviews were semi-structured and held in accordance with an interview guide. Each interview lasted 1-1,5 hour, was audio-recorded and subsequently transcribed. All interviews were held in the Danish language. The included interview quotes have therefore been translated from Danish to English by the paper authors.

As all interviews took place in Denmark what constitutes "international" is viewed from a Danish perspective. This can be useful to keep in mind when reading interview quotes that compare Denmark to other countries or when differences and similarities are mentioned. For example, when the interviewees make comparisons and statements about differences and similarities they seem to do so based on a number of taken-forgranted notions, such as the assumption that the Danish work culture is less hierarchical and more characterized by employee autonomy than work culture in other countries and that Danes in general are task oriented and prioritize efficiency.

Moreover, as all interviews were held in Danish it means that the two interviewers and the interviewee shared the same language and that much could be taken for granted with regard to contextual understandings, body language, humor, etc. It has been suggested that in such data collection situations (characterized by shared language and background) interviewer(s) and interviewee(s) create an 'ad hoc' national community as 'fellow travellers' $[4,5]$ that jointly aim to understand the world around them. 
However, it also means that taken for granted notions, national stereotypes, etc. might go unnoticed and that statements about national differences and similarities might be more expressed, because they are intended - and understood - as jokes in the interview situation. This is also useful to keep in mind when reading the in terview quotes in this paper.

Table 1. Overview of the participants

\begin{tabular}{|c|c|c|c|}
\hline $\begin{array}{l}\text { Inter- } \\
\text { viewee }\end{array}$ & Job title & Type of company & $\begin{array}{l}\text { Method for presenting } \\
\text { userinsights }\end{array}$ \\
\hline $\mathrm{A}$ & $\begin{array}{l}\text { Design re- } \\
\text { searcher }\end{array}$ & \multirow[t]{2}{*}{$\begin{array}{l}\text { Danish subdivision of a large inter- } \\
\text { national software development } \\
\text { company }\end{array}$} & \multirow[t]{2}{*}{$\begin{array}{l}\text { More than } 10 \text { years of } \\
\text { experience with the } \\
\text { persona method (interna- } \\
\text { tional personas) }\end{array}$} \\
\hline B & $\begin{array}{l}\text { Senior inter- } \\
\text { action design- } \\
\text { er }\end{array}$ & & \\
\hline $\mathrm{C}$ & $\begin{array}{l}\text { Design re- } \\
\text { searcher }\end{array}$ & $\begin{array}{l}\text { Large financial company with } \\
\text { headquarter in Denmark and subdi- } \\
\text { visions in Northern Europe }\end{array}$ & $\begin{array}{l}\text { Around } 5 \text { years of expe- } \\
\text { rience with the persona } \\
\text { method (international } \\
\text { personas) }\end{array}$ \\
\hline$\overline{\mathrm{D}}$ & $\begin{array}{l}\text { Head of digi- } \\
\text { tal experience } \\
\text { and global } \\
\text { marketing }\end{array}$ & $\begin{array}{l}\text { Large financial company with } \\
\text { headquarter in Denmark and subdi- } \\
\text { visions around the world }\end{array}$ & $\begin{array}{l}\text { Preferred method: Seg- } \\
\text { mentation; considers } \\
\text { using personas }\end{array}$ \\
\hline $\bar{E}$ & $\begin{array}{l}\text { Technical } \\
\text { writer }\end{array}$ & $\begin{array}{l}\text { Software development company } \\
\text { (financial systems), headquarter in } \\
\text { Denmark and subdivisions around } \\
\text { the world }\end{array}$ & $\begin{array}{l}\text { Development of a set of } \\
\text { international personas is } \\
\text { under consideration }\end{array}$ \\
\hline $\mathrm{F}$ & $\begin{array}{l}\text { Senior UX } \\
\text { researcher }\end{array}$ & $\begin{array}{l}\text { Software development company } \\
\text { (content management systems), } \\
\text { headquarter in Denmark and subdi- } \\
\text { visions round the world }\end{array}$ & $\begin{array}{l}\text { Development of a set of } \\
\text { international personas } \\
\text { has been initiated }\end{array}$ \\
\hline $\mathrm{G}$ & $\begin{array}{l}\text { Innovation } \\
\text { consultant }\end{array}$ & \multirow{3}{*}{$\begin{array}{l}\text { Organization that specializes in } \\
\text { development of digital health-care } \\
\text { solutions; many projects are funded } \\
\text { by EU and involve development of } \\
\text { solutions for several EU countries } \\
\text { at a time }\end{array}$} & \multirow{3}{*}{$\begin{array}{l}\text { The method for present- } \\
\text { ing user insights is cho- } \\
\text { sen from project to pro- } \\
\text { ject; exp erience with } \\
\text { national personas }\end{array}$} \\
\hline$\overline{\mathrm{H}}$ & $\begin{array}{l}\text { Innovation } \\
\text { consultant }\end{array}$ & & \\
\hline $\bar{I}$ & $\begin{array}{l}\text { Senior inno- } \\
\text { vation con- } \\
\text { sultant }\end{array}$ & & \\
\hline $\bar{J}$ & Consultant & \multirow{2}{*}{$\begin{array}{l}\text { Design agency that specializes in } \\
\text { tourism, events and city develop- } \\
\text { ment (project work for clients) }\end{array}$} & \multirow{2}{*}{$\begin{array}{l}\text { (National and interna- } \\
\text { tional) Personas often } \\
\text { constitute an important } \\
\text { result of the projects/for } \\
\text { the clients }\end{array}$} \\
\hline $\mathrm{K}$ & $\begin{array}{l}\text { User re- } \\
\text { searcher }\end{array}$ & & \\
\hline $\bar{L}$ & $\begin{array}{l}\text { Design re- } \\
\text { searcher }\end{array}$ & $\begin{array}{l}\text { Design agency that specializes in } \\
\text { product, service, graphical and } \\
\text { digital design (project work for }\end{array}$ & $\begin{array}{l}\text { One-page profiles of } \\
\text { actual users, with pic- } \\
\text { tures and quotes }\end{array}$ \\
\hline
\end{tabular}




\begin{tabular}{|c|l|l|l|}
\hline M & $\begin{array}{l}\text { Company } \\
\text { owner }\end{array}$ & $\begin{array}{l}\text { clients), headquarter in Denmark } \\
\text { and subdivisions around the world } \\
\text { Design agency that specializes in } \\
\text { national and international user } \\
\text { studies, UX design and test of solu- } \\
\text { tions (project work for clients) }\end{array}$ & $\begin{array}{l}\text { Profiles of actual users, } \\
\text { with pictures, quotes and } \\
\text { video sequences }\end{array}$ \\
\hline $\mathrm{N}$ & $\begin{array}{l}\text { Innovation } \\
\text { specialist }\end{array}$ & $\begin{array}{l}\text { Hearing aid company, headquarter } \\
\text { in Denmark and subdivisions } \\
\text { around the world }\end{array}$ & $\begin{array}{l}\text { Several years of experi- } \\
\text { ence with the persona } \\
\text { method (international } \\
\text { personas) }\end{array}$ \\
\hline $\mathrm{O}$ & $\begin{array}{l}\text { Audio engi- } \\
\text { neer }\end{array}$ & $\begin{array}{l}\text { Hearing aid company, headquarter } \\
\text { in Denmark and subdivisions } \\
\text { around the world }\end{array}$ & $\begin{array}{l}\text { Several years of experi- } \\
\text { ence with the persona } \\
\text { method (international } \\
\text { personas) }\end{array}$ \\
\hline
\end{tabular}

All interviewees work in companies, where digital solutions and/or software development is the main area of expertise or an important part of the products and product portfolio. They have many years of professional experience and are currently holding positions as design researchers, user experience (UX) researchers, innovation consultants and so on. A part of their job is to plan and carry out user studies. We will hereafter refer to them as user researchers. Table 1 provides an overview of the characteristics of the involved companies and participants.

The analysis of the interview data was structured into several rounds of analysis, where we used a thematic approach to organize the interview data into relevant units of text and themes, which were then interpreted and meaning condensed into our research findings [6].

An important part of the analysis was to distinguish between on the one hand, themes that the interviewees described as specific to international userstudies and on the other hand, themes related to national studies or inherent to all types of user research. In this paper, we focus on the practices and challenges that are specific to (or magnified by) the process of doing international user research.

\section{Empirical findings: A process perspective on international user studies}

In this section, we describe the strategies and practices that the companies and interviewees use when conducting international user studies.

We present our research findings in accordance with a process pers pective, because this was how the interviewees structured their practice descriptions. Thus, we look at the practices and challenges related to: (1) Initial planning, (2) International data collection, (3) Perceptions of end users, and (4) Presentation of user insights.

We do not address data analysis and implementation of user insights into design processes. This delimitation has been chosen, because the interviewees reported that the practices and challenges for these two process steps (i.e. analysis and implementation) were similar for national and international user studies. See [10] for research 
findings about the practices and challenges that relate to analysis and implementation of user insights in a national context.

\subsection{Initial planning}

There are a number of initial decisions and planning activities that have to be made before an international user study can commence.

\section{Strategic markets are prioritized.}

For companies operating on international markets a key decision is where, geographically, to collect data about the users. In most cases it is the management/client who makes the decision about which countries/regions to include in the study. The decision is typically based on what they consider to be the company's most important, strategic markets.

"It has to do with which strategic markets we want to be strong in. It is not so much that now we need to find four [countries] that are very different... of course India is included because they are very different from the US, but India is also included because they have a very large population who could use [our products] ..." (Innovation specialist, $N$ )

Thus, our analysis shows that the management's/client's decision about where to collect data is driven more by strategic business considerations and a marketorientation than by a focus on specific countries and national culture. Moreover, while it is not possible to say that it is a distinct pattern in the interview data, there does seem to be a slight difference in the way the interviewees use the words "markets" and "countries". When the word "market" is used, it seems to have more of a business connotation and to be used in connection with economic and pragmatic considerations. When the word "country" is used, it more intuitively invites the interviewee to talk about differences and similarities between countries/regions, and whether they matter or not for decision-making, data collection, and the product in question.

\section{Pragmatic issues sometimes overrule strategy.}

The interviewees report that normally it is quite clear which markets the management/client want to collect data about or what kind of knowledge they want to obtain about a particular geographical area. However, economic and pragmatic considerations related to, e.g., easier and cheaper travelling and language barriers mean that data sometimes is collected in other countries than originally decided. And also in other countries/regions than what might yield optimal knowledge. For example, it might be decided to do user interviews in England instead of an Eastern European country, because it reduces the language barrier for all involved.

\section{Strategies for planning the user study}


While it typically is the management/client that makes the decision about where to collect data, it is the task of the user researchers to plan the study. There are two different strategies for planning an international user study:

- A research design oriented strategy. Some user researchers plan the study to cover as many users and usergroups in the chosen countries/regions as thoroughly as the budget allows. This planning strategy is driven by the notion of validity and tends to lead to large-scale studies that involve many end users.

- A use oriented strategy. Other user researchers plan the study with the aim of being able to provide the employees (i.e., product designers, system developers, and marketing personnel) with insights about the important differences and similarities - between countries/regions, between the employees and their users, and between the many different types of users. When this planning strategy is used, the notion of validity still plays a role, but designing a study that addresses knowledge gaps is considered just as or more important than scientific method and rigor.

\subsection{International data collection}

The planning and the logistics that surround data collection for international user studies are much more demanding and time consuming than for national studies. This is because they typically involve: planning of international field studies, travel planning, use of external resources (e.g., agencies and translators from the countries where the study takes place), and many end users.

All this adds to the scale and complexity of carrying out this type of user studies. In this section we look at the interviewees' reported practices and concerns about data collection.

The importance of going to the field.

User researchers consider it very important to go to the field and participate in the data collection, for two reasons:

- To gain rich insights, i.e. to gain contextual knowledge and to interact directly with each of the users. It is also considered important for other employees, such as designers and developers to go to the field and meet the users.

- To ensure the quality of the data, i.e. to ensure the consistency of the data collection across countries and in general to ensure that the data collection is carried out in the way the user researchers has planned it. This is considered especially important if the data collection takes place in "new" or less familiar countries.

We have identified three different field study strategies. Thus, when user researchers go to the field they use one or more of the strategies mentioned below.

Strategy 1: The user researchers prefer to perform the data collection themselves, if possible from a language perspective. This approach provides much contextual knowledge about the particular country. Moreover, the experience of interacting with 
each of the users in person allows for a nuanced understanding of who the users are, how they live and work, and what their needs and motivations are.

Strategy 2: The user researchers perform the data collection with the help of a translator. This provides all the advantages of the abovementioned approach. However, different experiences are reported. Some state that it works well with a translator and especially if the translator is skilled and unobtrusive; others feel that they miss out on many nuances in what the user is saying and that they are unable to build a relationship with the user in the same way.

"It is always a challenge to use a translator because you never really have that $d i$ rect contact. You always depend on the translator. But when it is a good translator it works surprisingly well." (Design researcher, $L$ )

Strategy 3: The user researchers participate as observers despite language barriers. Five of the 15 interviewees mention that they have used this strategy, and while they consider it the least desirable option, it has advantages. Thus, even in cases where language barriers mean that they cannot understand the actual interaction between a local resource and a user, observation provides them with contextual knowledge and is a great aid to memory during the subsequent data analysis.

"We made sure that at least one of us was present at all interviews in all countries..." (Design researcher, $C$ )

\section{External resources: A matter of trust and control.}

International user studies often involve the use of external resources, such as:

- Recruiters/recruitment agencies

- User research agencies

- Local resource persons (e.g. freelance user researchers and translators)

- Danes with a relevant ethnic or educational background (e.g. a person with DanishKenyan ethnicity or a Danish anthropologist)

Choosing which external resources to use is an important decision. The user researchers state that it is essential for them to be able to trust that the external resources can perform and deliver the results of the study with the expected quality.

"...Just to find an agency that understands what we are talking about and...is able to do it with the quality we expect. We don't understand Russian for example... how can I know that what they are talking about is a good persona interview? A good observation? And they will probably report back with phrases and language that has many implicit understandings, which I might not get, so, yes, there are many challenges." (Senior interaction designer, B)

The user researchers prefer to use resources that they have used before. If this is not possible, e.g., because the study is performed in a country where they have not previously collected data, they prefer to participate in all or selected data collection activities to control the process.

As the data collection often involves the use of different agencies and resources in different countries, the external resources are typically briefed very thoroughly. Thus, 
to ensure that the data is collected in the same way and with the desired quality, the user researchers provide the external resources with:

- Detailed criteria for recruiting relevant users

- An interview guide with detailed explanations of why and how to ask each question

- Detailed guidelines for how to transcribe the interviews

"We used agencies in all four countries... it has the advantage that they speak the language and that they do it for us...but it of course also has the disadvantage that we used quite a lot of time on explaining very thoroughly what it was we wanted... When we delivered something to them there was a column with a question and then there was a long explanation of why we were asking about this and what we wanted to do with it...so we were very thorough and it also worked." (Design researcher, $C$ )

The common way of working with external resources is to be very thorough when choosing and briefing the resources. In general, the user researchers view international data collection as a collaborative effort and they work closely with the external resources throughout the data collection process to ensure that they get good quality data.

\section{Large-scale studies involving many end users.}

International user studies typically involve many end users. The prevailing approach is that data collection should cover the same number of users in each country/region that is included in the study. In other words, a research design oriented approach informed by the notion of validity is preferred. As one of the interviewees explain: "...of course, identical in the four countries" (Design researcher, C).

This means that if a company normally performs 15 user interviews for a national study, they will plan an international user study in four countries to cover 60 interviews.

Another example is from a user study that involved two countries, Denmark and an Eastern European country. It was prioritized that the same number of interviews should be held in both countries and that several user groups should be covered in each country. As a result, the number of interviews became quite extensive.

"...we did 72 qualitative interviews in total, half in Denmark and halfin Hungary." (Design researcher, $L$ )

\section{Strategies for recruitment of end users.}

As international user studies typically involve many end users, recruitment is a big task that takes up much time in the initial phases of a project. The user researchers choose between or mix two different strategies, depending on whether money or time is the more important aspect for the particular project.

The prevailing strategy is that the user researchers do all, most or some of the recruitment themselves. This is primarily because it is expensive to use external recruiters, but also because it often is possible (if time-consuming) for them to find the end users, based on customer lists or by drawing on their own social network. 
Another strategy is to use external recruiters to minimize the time spend, and also because it sometimes is not possible (or too time-consuming) to find relevant users in other countries.

The user researchers state that they give much thought to determining the recruitment criteria and that they typically use the same criteria to recruit the end users in all the involved countries/regions.

Concerns about national culture create barriers for data collection.

In addition to travel expenses, language issues, and data quality, concerns about national culture create barriers for data collection.

The user researchers express many concerns about lack of education in culture and about insufficient understandings of particular countries and national cultures.

“.... if you are going to do user studies, e.g., with Chinese people, it has to be in collaboration with somebody who knows something about China, about the Chinese market. Someone with an education. We wouldn't know enough." (Consultant, J)

They are especially worried about their lack of knowledge about Asia and Africa, but also areas that are geographically closer to Denmark such as Eastern European countries.

Some interviewees explain that they are much more comfortable doing user studies in countries and regions they are familiar with and where they do not perceive the culture to differ significantly from Danish culture. In some cases, the consequence of this respect for differences in national culture is that they do not conduct user studies in countries/regions they feel too unfamiliar with, even when these countries/regions are or could be relevant for their business.

“...India, China, Brazil, which are big markets, and yes, well, we know that we have a huge knowledge gap and we haven 't really done anything..." (Senior intera ction designer, $B$ )

Dealing with cultural differences in the data collection situation.

Our analysis shows that (too much) focus on differences in national cultural can give rise to concerns that significantly delimits a company's approach to international data collection. However, our analysis also shows examples of user researchers that acknowledge cultural differences as inherent to the data collection situation, also in a national context. They therefore see it as an important part of their job and skill set to be able to build a trusting and empathic relationship with the user, despite such differences (in nationality, educational background, work culture etc.).

"I try to achieve this closeness and that is difficult to achieve... [when] you meet a complete stranger and also from a different country...even in that cultural distance, which always is there, I have to establish empathy, trust, so she also can tell me about those aspects of her job where she is not so successful or where she does work arounds, how they tinker [with the system] ..." (Design researcher, A) 


\subsection{Perceptions of international end users}

In this section, we focus on perceptions of international end users, as an important outcome of the process as well as something that shapes the way the user study is planned and carried out.

\section{End users share many similarities across nationalities.}

The user researchers stress that one of the most important outcomes of international user studies is the insight that there are many similarities among end users across nationalities - as humans, consumers (of particular products), parents, workers, etc. This insight reflects a complex understanding of culture, i.e. an understanding that foregrounds the similarities of the users' everyday practices and the communities they participate in rather than national differences.

However, the user researchers also explain that employees have many preconceptions about different nationalities and the (large) role that national culture plays. It is therefore important to explicitly communicate insights about the similarities that the company's end users share across nationalities to the employees. Otherwise stereoty pical understandings of national differences might go unquestioned and influence the designers' work and ultimately the company's products.

'The user studies we have done have shown that at the personal level our end users have very similar motivations and approaches across borders... and this is very, very important and we make a big deal out of communicating this to employees." (Design researcher, $C$ )

"... [this disability] effects end users in the same way no matter where they live in the world." (Innovation specialist, $N$ )

\section{There are important differences in market conditions.}

There are also important differences among end users. Interestingly, it is pointed out that the most important differences often do not stem from national culture as such, but instead from differences in the economy, legislation, education, and societal structures and structural developments in different countries and regions.

"...it has to do with how the economy is... [and the] legislation. Legislation promotes a particular behavior in a particular country. And this is actually the two things [i.e. economy and legislation] that we have seen consequences of." (Design researcher, $C$ )

"...the differences that we see when we talk about [our end users] are that there can be a difference in how much money they have and this has something to do with whether the country they live in gives refunds, or health insurance, or whether the state is paying the full amount, and things like that. There are many different [health care] models in the different countries. And that effects this very much." (Innovation specialist, $N$ )

Knowledge about differences in national/regional market conditions cannot be obtained through user studies alone. Other types of internal data from databases, reports, social network, etc. as well as secondary sources about the socio-economic situation, 
societal structures and legal systems are also important in order to be able to distinguish between and understand the different types of users.

\section{Perceived differences in national culture are used to explain behavior.}

In addition to the complex understanding of culture demonstrated above, the interview data contains many examples of how perceived differences in national culture are used to explain expected and experienced behavior when collecting data in other countries.

The interviewees explain that challenges might arise because the communication partners have different expectations and may place different emphas is on efficiency and/versus politeness.

"I have just received an email from one of my colleagues who is trying to get [a user study] in Japan in place for me. He says that you just have to be aware that they are...traditionally speaking, they are not so willing to say what they really think ... you have to be aware of that, especially if their opinion is negative, so I have to take that into account." (Senior UX researcher, F)

"We have experienced the classical thing, in Brazil [they] were expressive about it and in Asia much shorter replies. We have used the same type of test in both places, and in Brazil they were very expressive, the Japanese gave very short statements, the Chinese were very polite and the Germans made jokes that were kind of dirty, which was a little strange, but it was also in Berlin [laughs] so maybe it was that." (Company owner, $M$ )

In the examples, perceived differences in communication styles are as sociated with and explained by national culture. The consequence of this is that more general understandings based on one factor, namely national culture, are foregrounded, while the more complex aspects of culture and the uniqueness of the actual situations and the individual communication partners are played down. As can be seen from our highlights in the quotes, the interviewees use words such as "traditionally speaking" and "the classical thing" to signal that they are aware of using general and somewhat stereotypical descriptions to explain the behavior of people from the countries in question.

National stereotypes develop over time as stories, examples, and jokes about the characteristics of people with a particular nationality are told and retold in the media, in literature, at social gatherings, etc. Moreover, they tend to cohere well with the experiences we have of interacting with people from these countries [11]. In this way, stereotypes come to influence the way we make sense of and talk about other nationalities. This can be problematic if stereotypical understandings gain too much explanatory power. Moreover, it can be problematic if stereotypes shape interpretations and decision-making in unreflective or unrecognized ways, e.g., when interacting with a person from a particular nationality or when making decisions about where and how to conduct international user studies.

\section{Linguistic simplifications create distance between people.}


In addition to stereotypes, language can in subtle, and often unconscious, ways serve to create distinctions between "us" and "them". For example, when the interviewees say that "those from Norway" prefer this or that "some lady from Mongolia" has that type of education, a distance is created. This is because the choice of the seemingly insignificant words "those" and "some" refer to a generalized group or person different from oneself - and therefore by implication more difficult to understand and relate to.

Likewise, communication theory shows that we always position ourselves as either: superior, equal, or subordinate in relation to other people when we communicate $[7,8]$. This can be seen in the above examples, where the generalization to "those" and "some" positioned the interviewee as superior and the others as subordinate. Other examples include the interviewees' use of linguistic images to explain that even though their company has a very diverse user group much data collection is conducted with "the white middle class" and "pale Europeans". Or to explain that the software their company produces is used by different groups, and therefore has to be designed so that it can be used by both "engineering types" and "a Russian cosmetologist". Such expressions are very powerful in communicating a point, because (positive and negative) stereotypes are used to create a vivid image. However, they also gloss over complex understandings and create distance (rather than empathy and identification) because of the use of general, value-laden categories.

Such linguistic images and simplifications cannot be avoided no matter how culturally competent one becomes. However, it is possible to become more aware of the language that one self and others use and to gain a better understanding of how linguistic structures create distance and cause people to take value-laden positions in relation to others.

This awareness of language is especially important when presenting the obtained user insights to the employees who have to use them for product design.

\subsection{Presentation of the user insights}

The companies that have participated in this research project use three different types of methods for presenting the user insights that they obtain through international user studies, namely personas, segmentation, or profiles of actual users. It is clear from our interview data that different types of companies use the three methods for different reasons.

- Personas is used by companies that wish to capture and apply the user insights for a period of time and for several purposes, i.e. in design activities, development projects, marketing campaigns, etc.

- Segmentation is used in companies where the company culture enforces a focus on logical arguments and decisions based on quantitative data.

- Profiles of actual users (rather than personas) are used by design agencies. For the design agencies we have talked to, the priority is to identify design insights for a particular client project. The profiles and user insights are not meant to live on after the project is over and therefore in-depth analysis leading to personas is not 
economically feasible unless they constitute an outcome, which the client is interested in and willing to pay for.

In this section, we look first at how the companies work with international personas and subsequently we describe the use of the two other methods.

\section{Strategies for creating international personas.}

The user researchers stress that the strength of the persona method is its ability to create recognition and empathic identification, but they disagree about how to achieve this in international personas. There are two different overall strategies for presenting international user insights as a set of personas:

(1) To create personas according to nationality. When this strategy is used there is typically one persona per country/region covered by the user study (e.g., if the user study was conducted in Denmark, India and USA, there will be one Danish, one Indian, and one US persona). In other words, this strategy results in country specific persona descriptions.

(2) To create personas according to other criteria, such as, e.g., differences in user preferences, profession, education level, level of involvement, learning styles, digital maturity, autonomy at the work place, etc. This is similar to the criteria that are used to create national personas. This results in general persona descriptions.

"We have tried two different models. One is to have a persona that is very focused on how people in this job think and what kind of goals they have. It [the persona description] can be quite general... the other model we have tried is to map different personas to different regions." (Senior interaction designer, B).

However, some compensate for what the choice of main strategy leaves out by adding text fields that delineate:

- What would be different about the persona compared to the country specific description if $s / h e$ was living in different countries/regions

- What would be unique to the persona compared to the general persona description if s/he was living in a particular country/region

This indicates that neither strategy is entirely successful. In line with this, one of the interviewed user researchers states that he would prefer if people did not have to read about the differences between, e.g., Japan and Europe, in added text fields and that he is planning to experiment with other ways of presenting the information about cultural differences.

When it comes to the content of the persona descriptions, some user researchers prefer to use pictures or drawings that contain very little background that could place the persona in a specific context. Moreover, they avoid geographical references in the text and they give the personas as general names as possible. The argument for this is that employees around the world should be able to recognize and use the personas and therefore the focus should be on the persona as a person rather than a person in a specific place. 
Other user researchers prefer to use pictures, names, titles, etc. which draw attention to and challenge the employees' stereotypical understandings of who the users are. The argument for this is to communicate the diversity of the users to the employees and therefore the focus is on the persona as a person who has both expected and unexpected features. One of the interviewees explain that she puts much effort into finding the right pictures for the personas and that she deliberately chooses pictures that challenge stereotypical understandings: "Generally for personas in firms: the top manager is a woman, the creative leader is a dark man. That is how you try to challenge stereotypes." (Design researcher, A).

\section{The choice of strategy is not only based on data.}

In general, the user researchers have strong opinions about which strategy they prefer. One of the interviewees for example states that: "I would rather not divide [personas] according to nationality." (Innovation specialist, $N$ ).

There are also several examples of how the choice of strategy for creating personas is made based on other considerations than the differences that emerge during data analysis. In one example, political considerations led to the use of strategy one, i.e. one persona for each of the company's main markets (even though nationality was not reflected as a significant difference in the data).

In another example the client had requested personas specifically to be able to develop 'the Swedish market', 'the Norwegian market', etc. and it was therefore natural to use strategy one. In other words, the decision to create personas based on nationality was made early on in the project, due to the client's way of conceptualizing their users in terms of markets that could be developed.

\section{Profiles and segments.}

Not all the companies we have talked to use personas. In the design agencies, for example, they do not use personas. Instead they create a profile of each user who has participated in the user study. The profile contains one or more pictures of the user and the home- or work context where the data collection took place as well as quotes and key insights. Thus, if the study covers 72 interviews, 72 user profiles are subsequently created - and in this particular example hung in a project room in order for the project team to be continuously reminded of the users and whom they were designing for.

Another company currently uses segmentation as the method for gathering and presenting user insights. Some companies conduct and use quantitative segmentation surveys, among other things, for planning a qualitative user study that results in personas. Yet again, in other companies they use and need both personas and segmentation as: "Personas are a strong tool to communicate user behavior and intentions, but many "number people" want to be able to use them to prioritize, so they want to know exactly how many "of those" there are in each country." (Innovation specialist, $N$ ). 


\section{Conclusion}

In this paper, we have presented the results of an empirical investigation of how companies conduct international user studies. Key findings are as follows.

Companies do not collect data about end users in all the countries/regions they operate in. Instead, they focus on a few strategic markets. These can be new markets the company wants to develop, but more often it is relatively well-known markets where the company is already conducting much of its business.

Our research also shows that for some geographical areas and countries the companies/user researchers have almost too much respect for the national culture. This in turn means that, even though it would be highly relevant for the business, there are parts of the world where they do not conduct user studies.

International user studies tend to be large-scale studies that involve many human resources, including company employees as well as external agencies, translators, etc. from the countries where the studies take place. The studies typically cover 2-4 countries/regions and many end users in each country/region. It is not uncommon that more than 50 qualitative interviews are conducted (in total), among other things, to ensure validity.

The preferred data collection method is field studies. If possible, user researchers choose to go to the field themselves to gain rich insights and to control the data collection process.

The main insights that companies gain from international user studies are (1) that there are many similarities among end users across nationalities and (2) that it often is more important to focus on and take differences in market conditions (i.e. legislation, socio-economic situation, healthcare system, education, etc.) into account rather than national culture per se. This indicates that one of the important outcomes of international user studies is a complex understanding of the role of culture. However, we also saw examples of stereotyping the users and of an "us versus them" attitude, even though the goal of the user studies is to gain a nuanced understanding of the users and to provide other employees with user insights that allow for recognition and empathic identification.

Companies are in the process of finding out how best to present the insights about international end users to the employees (i.e., product designers, project participants and marketing personnel). Currently, two strategies are used, namely to distinguish among end users (1) according to nationality or (2) according to other criteria (e.g., user preferences, education level, and IT maturity). However, neither strategy is entirely successful, as it either foregrounds the differences between nationalities or downplays the unique aspects of the different countries/regions.

Thus, so far, no best practice for incorporating both national differences and cross cultural similarities into persona descriptions, segmentations, etc. has been established.

This study contributes to the HCI literature with empirical findings about how companies conduct international userstudies and the specific practices and challenges hereof. In particular, we show that strategic considerations, perceived differences in 
national culture, and concerns about data quality play an important role in shaping and delimiting the approach that companies take to international user studies.

Our findings points to the need for more research that addresses how to plan and carry out user studies in countries that are perceived as culturally very different, how to ensure data quality and understand the notion of validity when conducting multicountry studies, and how to incorporate both national differences and cross-cultural similarities into persona descriptions, segmentations, etc.

Acknowledgement. This research is supported by InfinIT- Danish Network for Innovative Utilization of IT.

\section{References}

1. Boztepe, S.: Toward a Framework of Product Development For Global Markets: a uservalue-based approach, Design Studies, 28, pp. 513-533 (2007)

2. Camara, S. B., Oyugi, C., Abdelnour-Nocera, J., Smith, A.: Augmenting Usability: Cultural Elicitation in HCI. In: D. Katre et al. (Eds.): HWID 2009, pp. 46-56, IFIP AICT 316, (2010)

3. Clemmensen, T., Roese, K: An Overview of a Decade of Journal Publications about Culture and Human-Computer Interaction (HCI). In: D. Katre et al. (Eds.): HWID 2009, pp. 98-112 IFIP AICT 316, (2010)

4. Gabriel, Y.: Storytelling in organizations: Facts, fictions and fantasies. Oxford University Press, Oxford (2000)

5. Gertsen, M.C., Søderberg, A.M.: Intercultural Collaboration Stories: On narrative inquiry and analysis as tools for research in international business. Journal of International Business Studies, Vol. 42, pp. 787-804 (2011)

6. Kvale, S.: InterView. Hans Reitzel (1997)

7. Jensen, I.: Introduction to Cultural Understanding. Frederiksberg: Roskilde University Press. (2006)

8. Jensen, I.: "If Culture Is Practice ...? A Practice Theoretical Perspective on Intercultural Communication and Mediation". In: Finch, J., Nynäs, P. (eds.): Transforming Otherness. New Jersey: Transaction publishers, pp. 9-34. (2011)

9. Marcus, A., Gould, E.: Cultural Dimensions and Global User-Interface Design: What? So What? Now What? In: 6th Conference on Human Factors and the Web (2000)

10. Nielsen, L., Hansen, K.S: Personas is Applicable: A Study On the Use of Personas in Denmark. In: Proc. of CHI2014. ACM, Toronto, Canada, pp. 1665-1674, (2014)

11. Risberg, A., Søderberg, A.M., Tienari, J. \& Vaara, E.: National Talk: The construction of national stereotypes in a merging multinational. In: Søderberg, A.M. \& Vaara, E. (eds.), Merging Across Borders: People, cultures and politics, Copenhagen Business School Press, Denmark, pp. 61-86. (2003)

12. Putnam C., Rose, E., Johnson, E.J. Kolko, B.: Adapting User-Centered Design Methods to Design for Diverse Populations. Information Technologies and International Development. Vol. 5, 4, Winter, pp. 51-73 (2009)

13. Schumacher, R.: The Handbook of Global User Research. Morgan Kaufmann (2009)

14. Siegel, D.A., Dray, S.M.: International Contextual Field Research. In: Douglas, I, Liu, Z: Global Usability, pp. 57-88, Springer, London (2011) 
15. Walsh, T., Vainio, T., Varsaluoma, J.: Cross-Cultural Design of Mobile Mathematics Learning Service for South African Schools. In Proc. of Mobile Learning, 2014, (2014)

16. Young, P.A.: Integrating Culture in the Design of ICTs. In British Journal of Educational Technology 39, 1 pp. 6-17, (2008) 